Jurnal Keperawatan, Volume 9, No. 2, Agustus 2021, (Hal. 33-39)

\title{
FAKTOR RESIKO YANG BERHUBUNGAN DENGAN RIWAYAT SERANGAN PADA PENDERITA ASMA DI KABUPATEN MINAHASA SELATAN
}

\author{
Mercy Manese ${ }^{1}$, Hendro Bidjuni $^{2}$, Sefti Rompas ${ }^{3 *}$ \\ a (Mahasiswi PSIK FK Unsrat, Indonesia) \\ a(Dosen PSIK FK Unsrat, Indonesia) \\ a(Dosen PSIK FK Unsrat, Indonesia) \\ *Email : mercymanese01@gmail.com
}

\begin{abstract}
The background of this journal is that the asthma risk factors that influence the development and expression of asthma consist of internal factors (host factors) and external factors (environmental factors). The purpose of this study was to determine the risk factors associated with a history of attacks in asthmatic patients at motoring health centers, west motoring health centers and east motoring health centers. The research method uses descriptive research with a cross sectional approach with total sampling technique, in this study totaling 30 respondents, with research instruments consisting of allergens, respiratory factors, environmental factors and weather changes, with univariate and biavariate data analysis. The results showed that there was a relationship between allergen factors and a history of asthma attacks with $p$ value $=0.033<=0.05$, there was a relationship between respiratory infection factors and a history of asthma attacks with $p=0.011<=0.05$, there was no relationship between factors environment with a history of asthma attacks with $p$ value $=0.749<=0.05$, there is a relationship between weather change factors and a history of asthma attacks with $p=0.027<=0.05$. In conclusion, there is a relationship between allergen factors, infection factors and change factors with history of asthma attacks. Suggestions for the community to definitely know the triggering factors for bronchial asthma attacks so that they can prevent asthma recurrence and can avoid sudden changes in weather, for example from hot to cold (rainy season) by using thick clothing.
\end{abstract}

Keywords: Asthma risk trigger factors, history of asthma attacks

Abstrak: Latar Belakang dari jurnal ini adalah Faktor risiko asma yang mempengaruhi perkembangan dan ekspresi asma terdiri dari faktor internal (host factor) dan faktor eksternal (environmental factor). Tujuan penelitian ini adalah untuk mengetahyui faktor resiko yang berhubungan dengan riwayat serangan pada penderita asma puskesmas motoling, puskesmas motoling barat dan puskesmas motoling timur. Metode penelitian menggunakan penelitian deskriptif dengan pendekatan cross sectional dengan teknik total sampling, pada penelitian ini berjumlah 30 responden, dengan instrumen penelitian yang teridiri dari faktor alergen, faktor saluran pernafasan, faktor lingkungan dan perubahan cuaca, dengan analisa data univariat dan biavariat. Hasil penelitian didapatkan bahwa ada hubungan faktor alergen dengan riwayat serangan asma dengan nilai $\mathrm{p}=0,033<\alpha=0,05$, ada hubungan faktor saluran infeksi pernapasan dengan riwayat serangan asma dengan nilai $\mathrm{p}=0,011<\alpha=0,05$, tidak ada hubungan faktor lingkungan dengan riwayat serangan asma dengan nilai $p=0,749<\alpha=0,05$, ada hubungan faktor perubahan cuaca dengan riwayat serangan asma dengan nilai $p=0,027<$ $\alpha=0,05$.Kesimpulan, terdapat hubungan faktor alergen, faktor infeksi dan faktor perubahan dengan riwayat serangan asma. Saranmsyarakat secara pasti mengetahui faktor pencetus serangan asma bronkial agar dapat mencegah kekambuhan asma dan dapat menghindari perubahan cuaca yang mendadak misalnya dari panas ke dingin (musim hujan) dengan menggunakan pakaian tebal.

Kata Kunci : Faktor pemicu risiko asma, riwayat serangan asma 


\section{PENDAHULUAN}

Penyakit asma ialah gangguan inflamasi kronik pada jalan napas. Inflamasi kronik dapat menyebabkan peningkatan hiperresponsif jalan napas yang ditandai dengan wheezing, sulit bernapas, dada sesak dan batuk (Lewis, Heitkemper, Dirksen, O’brien \& Buceher, 2007).

Dampak kecemasan dan depresi salah satunya adalah penurunan kualitas hidup (Kullowatz, Kanniess, Dahme, Magnussen, \& Ritz, 2007). Selain memberikan dampak fisik, psikologis, ataupun fungsional, Asma juga berpengaruh terhadap kualitas hidup penderitanya bahkan meningkatkan angka morbiditas (To et al., 2013).

Semakin besarnya polusi yang terjadi di lingkungan indoor dan outdoor, serta perbedaan cara hidup yang kemungkinan di tunjang dari sosioekonomi individu, karena lingkungan dalam rumah mampu memberikan kontribusi besar terhadap faktor pencetus serangan asma, maka perlu adanya perhatian khusus pada beberapa bagian dalam rumah. Perhatian tersebut ditujukan pada keberadaan alergen dan polusi udara yang dapat dipengaruhi oleh faktor kondisi lingkungan rumah dan perilaku keluarga. Komponen kondisi lingkungan rumah yang dapat mempengaruhi serangan asma seperti keberadaan debu, bahan dan desain dari fasilitas perabotan rumah tangga yang digunakan (karpet, kasur, bantal), memelihara binatang yang berbulu (seperti anjing, kucing, burung), dan adanya keluarga yang merokok dalam rumah. Disamping itu agent dan host memiliki andil seperti: makanan yang disajikan, riwayat keluarga, perubahan cuaca, jenis kelamin, (Craig, 2010).

Serangan asma seringkali terjadi apabila individu tidak bisa mengendalikan dan mencegah kontak dengan faktor faktor pemicu serangan asma seperti, faktor perubahan cuaca, infeksi saluran pernapasan, tekanan jiwa, kegiatan jasmani/olahraga, obat-obatan, polusi udara, lingkungan kerja (Craig, 2010).
Berdasarkan uraian di atas asma menjadi masalah kesehatan yang banyak di derita di Indonesia termasuk di dalamnya Provinsi Sulawesi Utara dan didalamnya Kabupaten Minahasa Selatan kecamatan Motoling, kecamatan Motoling Barat dan kecamatan Motoling Timur. Data penyakit asma yang ada di Puskesmas Motoling, Puskesmas Motoling Barat dan Puskesmas Motoling Timur dari bulan Januari - Maret berjumah 30 pasien. Untuk Puskesmas Motoling berjumlah 13 pasien, Puskesmas Motoling Barat 9 pasien dan Puskesmas Motoling Timur 8 pasien. Untuk itu peneliti tertarik untuk melakukan penelitian mengenai faktor resiko yang berhubungan dengan riwayat serangan asma di Kabupaten Minahasa Selatan.

\section{METODE}

Penelitian ini menggunakan penelitian deskriptif. Populasi pada penelitian ini ialah pasien asma yang terdata di Puskesmas Motoling, Puskesmas Motoling Barat, Puskesmas Motoling Timur dengan jumlah 30 responden dengan kriteria inklusi terdiagnosa asma yang tercatat dalam rekam medis dan bersedia menjadi sampel penelitian. Pengambilan sampel pada penelitian ini keselurahan dari populasi atau total sampling. Instrumen dalam pengumpulan data dan informasi pada responden, peneliti menggunakan pengumpulan data dalam bentuk kuesioner yang terbagi dari faktor alergen, faktor infeksi saluran perafasan, faktor lingkungan, perubahan cuaca dan riwayat serangan asama. Pengolahan data yang diperoleh dari hasil penelitian ini diolah secara manual dan dianalisis secara statistik melalui komputerisasi Chi-Square.

Dalam melakukan penelitian, peneliti menggunakan etika penelitian yang terdiri dari Informed consent, Anonymity (tanpa nama), dan Confidentially. Dalam menggunakan etika penelitian, peneliti menjelaskan bahwa telah mendapat persetujuan dari tempat penelitian yaitu Puskesmas Motoling dengan nomor: 001/186/PKM-MOT-Ket/V/2021, 
Puskesmas Motoling Barat dengan nomor: 001/328/PKM-MB/S-Ket/VII/2021,

Puskesmas Motoling Timur dengan nomor: 001/225/PKM-MT/SU/VI/2021. Analisa data dilakukan terhadap variabel penelitian untuk meneliti tampilan distribusi frekuensi dan presentase dari tiap-tiap variabel. Sehingga, menunjukan hasil ada hubungan faktor alergen, faktor infeksi saluran pernafasan, dan faktor perubahan cuaca dengan riwayat serangan asma.

\section{HASIL}

Tabel 1. Karakteristik Responden

\begin{tabular}{llcc}
\hline No & Variabel & $\mathbf{f}$ & \% \\
\hline 1. & Usia & & 3.3 \\
& 5-11 Tahun & 1 & 16.7 \\
12-16 Tahun & 5 & 50.0 \\
17-25 Tahun & 15 & 3.3 \\
26-35 Tahun & 1 & 6.7 \\
36-45 Tahun & 2 & 6.7 \\
46-55 Tahun & 2 & 13.3 \\
> 55 Tahun & 4 & \\
2.nis Kelamin & & 53.3 \\
Laki-Laki & 16 & 46.7 \\
Perempuan & 14 & \\
Pendidikan & & 13.3 \\
SD & 4 & 10.0 \\
SMP & 3 & 46.7 \\
SMA & 14 & 13.3 \\
Diploma & 4 & 10.0 \\
S1 & 3 & 6.7 \\
S2 & 2 & \\
Pekerjaan & & 100 \\
PNS & 3 & 6.7 \\
Pegawai Swasta & 2 & 10.0 \\
Pegawai BUMN & 3 & 3.3 \\
IRT & 1 & 3.3 \\
Tidak Bekerja & 1 & 63.3 \\
Siswa & 19 & 3.3 \\
Wiraswasta & 1 & \\
\hline
\end{tabular}

Sumber : Data Primer, 2021.

Karakteristik responden berdasarkan usia, responden terbanyak berada pada usia 17-25 tahun dengan jumlah 15 responden $(50.0 \%)$, sedangkan yang paling sedikit berada pada usia 5-11 tahun dan 26-35 tahun masing-masing dengan jumlah 1 responden $(3.3 \%)$. Karakteristik responden berdasarkan jenis kelamin, jenis kelamin terbanyak berada pada jenis kelamin laki- laki dengan jumlah 16 responden (53.3\%). Karakteristik responden berdasarkan tingkat pendidikan, tingkat pendidikan responden terbanyak berada pada tingkat pendidikan SMA dengan jumlah 14 responden $(46.7 \%)$, sedangkan yang paling sedikit berada pada tingkat pendidikan S2 dengan jumlah 2 responden (6.7\%). Karakteristik responden berdasarkan status 
pekerjaan, status pekerjaan responden terbanyak berada pada SMA dengan jumlah 19 responden $(63.3 \%)$, sedangkan yang paling sedikit berada pada IRT, Tidak Bekerja dan Wiraswasta masing-masing dengan jumlah 1 responden(3.3\%).

\section{Tabel 2. Hasil Penelitian}

\begin{tabular}{llcc}
\hline No & Faktor Serangan Asma & $\mathrm{n}$ & $\%$ \\
\hline 1. & Faktor Alergen & & \\
& Tidak Terpapar & 17 & 56.7 \\
& Terpapar & 13 & 43.3 \\
\hline 2. & Faktor Infeksi Saluran Pernafasan & \\
& Tidak Terpapar & 16 & 53.3 \\
& Terpapar & 14 & 46.7 \\
\hline 3. & Faktor Lingkungan & & \\
& Tidak Terpapar & 14 & 46.7 \\
& Terpapar & 16 & $53 ` 3$ \\
\hline 4. & & \\
& Taktor Perubahan Cuaca & 15 & 50.0 \\
& Terpapar & 15 & 50.0 \\
\hline 5. Riwayat Serangan Asma & & \\
& Tidak Ada & 17 & 56.7 \\
Ada & 13 & 43.3 \\
\hline
\end{tabular}

Karakteristik responden terbanyak faktor alergen berada pada tidak terpapar dengan jumlah 17 responden $(56.7 \%)$, sedangkan responden yang paling sedikit berada pada faktor alergen terpapar dengan jumlah 13 responden (43.3\%). Karakteristik responden terbanyak faktor infeksi saluran pernapasan berada pada tidak terpapar dengan jumlah 16 responden $(53.3 \%)$, sedangkan responden yang paling sedikit berada pada faktor infeksi saluran pernapasan terpapar dengan jumlah 14 responden $(46.7 \%)$, sedangkan responden yang paling sedikit tidak terpapar dengan jumlah 14 responden $(46.7 \%)$.

Karakteristik responden yang terpapar atau tidak terpapar perubahan cuaca masing-masing dengan jumlah 15 responden $(50 \%)$.Karakteristik responden terbanyak yang tidak ada riwayat serangan asma dengan jumlah 17 responden $(36.7 \%)$, sedangkan responden yang paling sedikit ada serangan dengan jumlah 13 responden $(43.3 \%)$.

\section{PEMBAHASAN}

\section{Faktor Alergen Dengan Riwayat Serangan Asma}

Berdasarkan Hasil analisis yang dilakukan dengan menggunakan uji ChiSquare menunjukan nilai $\mathrm{p}=0,033<\alpha=$ 0,05 , terdapat hubungan faktor alergen dengan riwayat serangan asma.

Hasil penelitian Craig (2010) menyebutkan bahwa sensitisasia eroallergen terjadi pada kebanyakan pasien asma dan persentase lebih tinggi pada pasien denganasma ringan dan moderat. Persentase sensitisasi aeroalergen yang atopik pada asma berat tampaknya kurang. Sebagian besar pasien dengan asma ringan sampai sedang dan bahkan yang parah memiliki riwayat alergi. Sebanyak $90-95 \%$ pasien dengan asma memiliki sensitisasi aeroallergen dengan pola yang bervariasi tergantung dari status ekonomi, identifikasi etnik, lokasi tempat tinggal, dan onsetasma. 
Hasil penelitian Wahyu, 2013 menunjukkan ada hubungan yang bermakna antara allergen dengan kejadian serangan asma, dimana $\mathrm{p}$ value $=0,002$. Asma akibat alergi bergantung pada respons IgE yang dikendalikan oleh limfosit $\mathrm{T}$ dan $\mathrm{B}$ dan diaktifkan oleh interaksi antara antigen dengan molekul IgE yang berikatan dengan sel mast. Sebagian besar alergen yang mencetuskan asma bersifat airborne dan supaya dapat menginduksi keadaan sensitivitas, alergen tersebut harus tersedia dalam jumlah banyak untuk periode waktu tertentu, (Harrison, 2000).

Asma yang saat ini dipandang sebagai penyakit inflamasi jalan nafas memang tidak bisa lepas dari pengaruh alergen (Suyono, 2001). Alergen spesifik sifatnya sangat subyektif, tergantung kepekaan masing-masing penderita asma. Paparan berulang terhadap suatu jenis alergen spesifik akan menyebabkan reaksi alergi langsung, seperti reaksi hipersensitivitas tipe I pada asma (AAFA, 2008).

Untuk menghindari faktor alergen juga dapat dilakukan dengan menggunakan masker saat penderita akan melakukan aktivitas yang berhubungan langsung dengan debu dan asap pembakaran. Dimana hal tersebut sering dijumpai pada saat musim panen yang bertepatan dengan dilakukannya penelitian. Masker juga dapat digunakan para penderita saat akan bepergian yang bertujuan untuk menghindari asap kendaraan. Selain upaya penanggulangan diatas, upaya lain yang dapat diberikan adalah berupa informasi agar responden rutin berkunjung untuk memeriksakan asma yang diderita dan juga agar selalu siap obat dalam keadaan apapun. Bagi penderita yang sudah mengetahui penyebab serangan asma pada dirinya, mereka lebih banyak menghindari penyebab tersebut karena takut serangan asma tersebut akan terulang kembali.

\section{Faktor Infeksi Saluran Pernafasan Dengan Riwayat Serangan Asma}

Berdasarkan hasil analisis yang dilakukan dengan menggunakan uji ChiSquare menunjukan nilai $\mathrm{p}=0,011<\alpha$ $=0,05$, terdapathubungan faktor infeksi saluran peranapasan dengan riwayat serangan asma.

Penelitian ini sejalan dengan Abraham (2007) menyatakan bahwa infeksi saluran napas dapat menyebabkan serangan asma dengan $p$-value $=0,001$. Selain itu menurut penelitian Kusbiantoro (2005) menunjukkan bahwa faktor pencetus serangan asma yang terbanyak adalah ISPA diikuti oleh paparan asap dan udara dingin. Penelitian ini tidak sejalan dengan Luh (2012) yang menyatakan bahwa tidak ada perbedaan proporsi terjadinya serangan asma pada pasien yang mengalami infeksi pernapasan dengan $p$-value $=0,598$, yang artinya tidak ada hubungan antara paparan infeksi pernapasan dengan terjadinya serangan asma.

Menurut penulis infeksi saluran pernapasan dapat menyebabkan serangan asma. Batuk, pilek, demam dapat menyebabkan inflamasi sehingga meningkatkan hipperresponsif pada sistem bronkial. Berdasarkan hasil wawancara terhadap responden, responden selalu mewaspadai gejala-gejala akan batuk, pilek dan demam dengan mengobati gejala tersebut. Jenis infeksi saluran pernapasan yang berhubungan dengan serangan asma bronkial dan memiliki risiko paling besar adalah batuk. Apabila infeksi saluran pernapasan tersebut berat maka kemungkinan mendapat serangan asma juga besar. Penulis menyarankan agar responden menjauhi kontak dengan orang yang sedang mengalami infeksi sal uran napas seperti batuk, pilek, demam dengan menggunakan masker sebagai proteksi awal dan bila mengalami infeksi agar segera mendapat pengobatan.

\section{Faktor Lingkungan Dengan Riwayat Serangan Asma}

Berdasarkan hasil analisis yang dilakukan dengan menggunakan uji Chi- 
Square menunjukan nilai $\mathrm{p}=0,749>\alpha$ $=0,05$, tidak ada hubungan faktor lingkungan dengan riwayat serangan asma.

Faktor lingkungan yang berpengaruh adalah alergen, sensitisasi lingkungan kerja, asap rokok, polusi udara, infeksi pada pernapasan, diet, status sosial ekonomi maupun besarnya keluarga individu yang kecenderungan lalu berkembang menjadi asma dan menyebabkan terjadinya eksaserbasi dan atau menyebabkan gejalagejala asma yang menetap (Syahira, 2015). Penelitian sejalan (Andi, 2019), yaitu terdapat pengaruh Hubungan Lingkungan dengan Derajat Asma yang dilakukan di Rumah Sakit Umum Andi Makkasau Daerah Kota Parepare.

Penelitian tidak sejalan dengan penelitian (Yasmin, 2013) bahwa terdapat hubungan antara lingkungan dengan kejadian Asma bronkial di wilayah kerja Puskesmas Tamalate kota Gorontalo dengan $p$ value 0,000. Penderita Asma dapat terserang bahan - bahan pencetus ini secara tidak sengaja misalnya debu rumah tangga, debu kasur/bantal kapuk, ataupun karena hobi atau karena pekerjaan atau profesi (Fattore, 2015).

\section{Faktor Perubahan Cuaca Dengan Riwayat Serangan Asma}

Berdasarkan hasil analisis yang dilakukan dengan menggunakan uji ChiSquare menunjukan nilai $\mathrm{p}=0,027>\alpha$ $=0,05$, terdapathubungan faktor perubahan cuaca dengan riwayat serangan asma.

Penelitian ini sejalan Purnomo (2008) yang menyatakan bahwa terdapat hubungan antara perubahan cuaca dengan serangan asma bronkial. Penelitian Aini (2012) menghasilkan korelasi perubahan cuaca dengan kekambuhan asma. Penelitian Hasma (2012) juga menyatakan bahwa ada hubungan antara perubahan cuaca dengan serangan asma bronkial .

Kondisi cuaca seperti temperatur dingin, tingginya kelembaban dapat menyebabkan kekambuhan asma, epidemik ini menyebabkan asma menjadi lebih parah dan meningkatkan partikel alergenik
(Rachelefsky, 2006). Perubahan tekanan dan suhu memperburuk asma bronkiale, sesak nafas dan pengeluaran lendir yang berlebihan terjadi ketika kelembaban tinggi, hujan, danselama musim dingin (Dahlan Z, 2000).

Kondisi cuaca seperti temperatur dingin, tingginya kelembaban dapat menyebabkan kekambuhan asma, epidemik ini menyebabkan asma menjadi lebih parah dan meningkatkan partikel alergenik (Ramaiah, 2006). Asumsi peneliti terkait dengancuaca sebagai faktor yang pencetus terjadinya serangan asma bronkial bahwa, jika seorang berada pada daerah-daerah dingin beresiko terkena serangan asma bronkial. Sekalipun berdasarkan karena cuaca sebagai faktor pencetus terjadinya serangan asma namun juga ruangan yang ber AC dapat mencetuskan terjadinya serangan asma bronkial.

\section{SIMPULAN}

Terdapat hubungan faktor alergen, faktor infeksi saluran pernapasan, dan faktor perubahan cuaca dengan riwayat serangan pada penderita asma di Puskesmas Motoling, Puskesmas Motoling Barat Dan Puskesmas Motoling Timur. Diharapkan Puskesmas memberikan KIE kepada pasien untuk mengetahui faktor pencetus serangan asma, menghindari perubahan cuaca yang mendadak dengan menggunakan pakaian tebal agar terhindar dari serangan asma.

\section{DAFTAR PUSTAKA}

Abraham, 2007. Infeksi Saluran Pernafasan Dengan Riwayat Serangan Asma Pada Pasien IRJ Poli Paru RS Paru Jember, Jurnal

Asthma and Allergy Foundation of America (AAFA). (2008). Asthma triggers. Diunduh dari www.aafa.org

Andi K. (2019) Hubungan Antara Karakteristik Penderita Dengan Derajat Asma Bronkial Di Rumah 
Sakit Umum Daerah Andi Makkasau Kota Parepare

Craig, T. J. (2010), Aeroallergen sensitizatiom in asthma: Prevalence and correlation with severity. Allergy and asthma proceeding.

Dahlan Z. 2000. DahlanZ. PenekananDiagnosisdanTerapiAsma denganMetodeObjektif.CerminanDu niaKedokteran.

Fattore GL, Santos Carlos Antonio de ST, Barreto ML. Sosioeconomic and Environmental Determinants of Adolescent Asthma in Urban Latin America: an EcologicalAnalysis. Cad. Saude Publica; 2015: 31(11): 2367-2378.

Harrison. 2000. Prinsip- Prinsip Ilmu Penyakit Dalam Edisi 1. Jakarta : EGC.

Hasma, 2012. Faktor Pencetus Serangan Asma Bronchial di Rumah Sakit Dr. Wahidin Sudirohusodo Makasar. Jurnal Stikes Nani Hasanudin Makasar Vol. 1 (3)

KusbiantoroH., 2005.Hubungan polusiudaradanperubahancuacadeng ankejadianseranganasma.Jakarta: FKUI.

Kullowatz, A., Kanniess, F., Dahme, B., Magnussen, H., \& Ritz, T. (2007). Association of depression and anxiety with health care use and quality of life in asthma patients. Respiratory Medicine, 101(3), 638-644. http://doi.org/10.1016/j.rmed.2006.0 6.002

Lewis, S., Heitkemper. M., Dirksen, s; O' Brien, P., \& Bucher, L. (2007). Medical - Surgical nursing : Assessment and management of clinical problems. Missouri : Elsevier

Ni Luh Putu Ekarini. 2012. Analis FaktorFaktor Pemicu Dominan Terjadinya Serangan Asma Pada Pasien Asma

Purnomo. 2008. Faktor-faktor risiko yang berpengaruh terhadap kejadian asmabronkial(StudiKasusdiRSKabup atenKudus).Tesis.Semarang:Universi tasDiponegoro.
Rachelefsky, Gary. 2006. Penanganan Asma pada Anak. Jakarta: Bhuanana IlmuPopuler.

Ramaiah S. 2006. Asma - Mengetahui Penyebab, Gejala dan Cara Penanggulangannya. Jakarta: Gramedia

Suyono, S., 2001, Buku Ajar Penyakit Dalam, Jilid II, Jakarta, Balai Pustaka

Syahira, Indra Y, Miftah A. 2015. Hubungan Tingkat Pengetahuan Asma dengan Tingkat Kontrol Asma di Poliklinik Paru RSUD Arifin Achmad Pekanbaru. Pekanbaru: Fakultas Kedokteran; 2015

To, T., Stanojevic, S., Feldman, R., Moineddin, R., Atenafu, E. G., Guan, J., \& Gershon, A. S. (2013). Is asthma a vanishing disease? A study to forecast the burden of asthma in 2022. BMC Public Health, 13(1), 254. http://doi.org/10.1186/1471-2458-

13-254, Diakses tanggal 10
September 2018, 09. 47 Wita.

Wahyu, 2013. Analisa faktor-faktor pencetus derajat serangan asma pada penderita Asma di puskesmas perak kabupaten jombang tahun 2013, Jurnal

http://ejurnal.stikespemkabjombang.a c.id/index.php/Juli-

2013/article/view/33/63, Diakses tanggal 10 September 2018, 09. 47 Wita

Yasmin, 2013, Hubungan antara lingkungan dengan kejadian Asma bronkial di wilayah kerja Puskesmas Tamalate kota Gorontalo 